\title{
Effectiveness of Structured Nursing Teaching Program on Outcomes of Chronic Low Back Pain Patients Undergoing Radiofrequency Ablation
}

\author{
Ghada Hassan Ahmed ${ }^{1} \quad$ Neama Mamdouh Mostfa ${ }^{1} \quad$ Shaymaa Sayed Khaliil ${ }^{1} \quad$ Hanan Abd Allah Abozeid*2 \\ Heba M. Fahmy ${ }^{2}$ Abd Elraheem Elawamy ${ }^{3}$ \\ 1.lecturers of Medical-Surgical Nursing, Faculty of Nursing, Assiut University, Egypt \\ 2. lecturers of Gerontological Nursing, Faculty of Nursing, Assiut University, Egypt \\ 3.Assistant professor of Anesthesia and Pain Management, Faculty of Medicine, Assiut University, Egypt
}

\begin{abstract}
Background: Chronic low back pain is a full disorder that considers an important health problem. Aim: To evaluate the effectiveness of structured teaching program on outcomes of chronic low back pain patients undergoing radiofrequency ablation. Methods: A quasi-experimental research design has been utilized. Setting: Anesthesia and pain management department at the main Assiut University Hospital. Sample: Sixty low back pain patients undergoing radiofrequency ablation. They were randomly assigned in two groups of 30 patients each. Tools: three tools were utilized: Tool I: Structured interview patients' questionnaire. Tool II: Visual analogue pain scale and Tool III: "Modified Oswestry low back pain disability questionnaire" in addition, structured nursing teaching program. Results: More than half (53.3\%) of the case group their age was from 18 to $<55$ years, and the rest of them $(46.7 \%)$ were older adults aged 55 years and more. $80 \%$ of the case group had good knowledge post implementation of the program. (100\%) of the case group had worst pain intensity level which decrease to $(46.7 \%)$ post program. $40 \%$ of case group had sever disability, which decreased to $30 \%$ post implementation of the program. there were significant relation between pain analogue scale and Oswestry low back pain disability scale in pre and post structured nursing teaching program regarding to occupation Conclusion: Structured nursing teaching program had an effective strategy to improve the patients' outcomes through increasing patients' knowledge, and decreasing both pain intensity and physical disability in the case group versus the control group. Recommendation: Supervised structured teaching program should be carried out for all patients undergoing radiofrequency ablation about pre-and post-procedure instructions and helpful hints for a healthy back when standing, walking, sitting, sleeping, and lifting.
\end{abstract}

Keywords: Chronic low back pain, Radiofrequency ablation, structured nursing teaching program.

DOI: $10.7176 / \mathrm{JHMN} / 65-08$

Publication date: August $31^{\text {st }} 2019$

\section{Introduction:}

Low back pain is the most common pain in the modern society with estimates of lifetime prevalence as high as $84-90 \%$ and the 5 -year recurrence rate as high as $69 \%$. Numerous structures can contribute to lower back pain including but not limited to the lumbar vertebral bodies, intervertebral discs, facet joints, spinal nerves, the surrounding muscles, and ligaments. It appears with great consequences to the functional capacity of the influenced people (Kennedy et al., 2014).

Chronic back pain is defined as pain that continues for 12 weeks or more, even after an initial injury or underlying cause of acute low back pain has been treated. Around 20 percent of individuals influenced by acute low back pain develop chronic low back pain with persistent symptoms at one year (Hofmann et al., 2017).

Pain relief, either medically or surgically, is a basic human right or is a duty of physicians especially anesthesiologists working in pain clinics (Imani \& Safari, 2011). Radiofrequency ablation (RFA) is a regularly utilized treatment in pain clinics for chronic low back pain since the early 1970s. It is a safe, proven means of interrupting pain signals. Radiofrequency current is used to heat up a small volume of nerve tissue ablation, there by interrupting pain signals from that particular area (Crystian et al., 2018).

Radiofrequency ablation (RF) may be continuous RF (CRF) or pulsed RF (PRF). CRF uses high-frequency alternating current to induce coagulative necrosis in the target tissue. Tissue destruction occurs with probe temperatures between $60^{\circ} \mathrm{C}$ and $80^{\circ} \mathrm{C}$. Conversely,, PRF utilizes RF current in short (20 ms), high-voltage bursts; the "silent" phase $(480 \mathrm{~ms})$ of PRF allows time for heat elimination, generally keeping the target tissue underneath $42^{\circ} \mathrm{C}$. The whole radiofrequency ablation technique usually takes 30 to 90 minutes (Kapural et al., 2013).

Teaching patients is one of the most challenging and rewarding parts of providing nursing instructions. Preprocedure patient's instructions for radiofrequency ablation include; teaching patients not to eat 4 hours or drink 2 hours prior to the procedure, and may take routine morning medications with a small amount of water. Inquire as to whether he/she take fish oil or Vitamin E supplementation, or Warfarin, or any other blood thinner, you should stop these 5 days prior to the ablation. Illuminate patients that they might be mentioned to obtain laboratory work 
and an electrocardiogram (ECG) prior to procedure, and advising them regarding the follow-up appointment for roughly 10 days to 2 weeks after the procedure. (Malekian et al., 2016).

Post-procedure patient's instructions include; instruct the patient to rest and limit activity the remainder of the day of the procedure, return to normal diet as tolerated, resume aspirin and other anticoagulants the first day after the injection. Moreover, the dressing may be removed after 24 hours and may take shower immediately, but avoid baths/ hot tubs for the first 2 days after the procedure due to increased risk of infection. Illuminate the patients that they may utilize ice packs over the injection site -20 minutes on, then 20 minutes off, repeat this cycle as required and not to apply the cold packs to the numb areas following injection (Kapural et al., 2017).

Orientation of the patient of common side effects following the procedure as decreased pain and perhaps some numbness for 4 to 8 hours due to the local anesthetic, possible increased overall pain for 2-4 weeks, discomfort at the injection site, a small amount of bleeding at the injection site, and back stiffness. Tell the patient all of the side effects should disappear within 1 to 3 days after the procedure, instruct patient to keep a diary of pain following the procedure, this will help when discussing the results of procedure with the doctor. Notify physician if increase in pain or legs are getting weak, chills or fever of $38.3 \mathrm{C}$ or greater, redness or drainage at the injection site, headache that does not go away, and any other unusual or new symptoms. Moreover, teach and demonstrate with the patient proper posture mechanics when standing or walking, driving, sitting, lifting, and sleeping to avoid recurring back pain (Gomes et al., 2015).

\section{Significance of the study:}

Chronic low back pain is a common problem and more than $80 \%$ of the global population will experience low back pain at least once in their lifetime. RFA is a commonly used treatment in pain clinics for chronic low back pain. These patients are in need for special nursing care to minimize their complications (Koes et al., 2010). It is important to patients to gain more knowledge about the radiofrequency Ablation that may minimize low back pain, which consider the main nursing goal for those patients. Accordingly, the point of this study was to evaluate the effectiveness of structured nursing teaching program on outcomes of chronic low back pain patients undergoing radiofrequency ablation.

\section{Aim of the current study:}

To evaluate the effectiveness of structured nursing teaching program on outcomes of chronic low back pain patients undergoing radiofrequency ablation.

\section{Research hypotheses:}

There will be significantly improvement in the patients' outcomes through increasing patients' knowledge, and decreasing both pain intensity and physical disability in the case group versus the control group after implementation of structured nursing teaching program

\section{Patients and method:}

\subsection{Research design:}

A quasi-experimental research design was utilized in this study

\subsection{Setting:}

Department of the anesthesia and pain management at the main Assiut University Hospital.

\subsection{Sample:}

A purposeful sixty patients were included, and met the following criteria; were having lumbar facet joints, sacroiliac joints, and discogenic low back pain, pulsed or continuous radiofrequency ablation, the age from 18 years and more, both sexes (male and female), and Pain persistent for $\geq 3$ months before intervention. Exclusion criteria were; patients with contraindication to local injection as (active infections, coagulopathy, allergy to local anesthesia and pregnancy)

The sample divided randomly into two equal groups; the case and the control groups (30 patients for each). The case group received structured nursing teaching program plus radiofrequency ablation, while the control group received radiofrequency ablation only.

Sample size was calculated based on the previous year (2018) census report of radiofrequency ablation for low back pain patients at the main Assiut University Hospital. Total numbers of radiofrequency ablation for low back pain patients was 180 patients. The researchers collected data from the selected patients through one month. Sample size was calculated utilizing the following Equation according to Steven, (2012) 


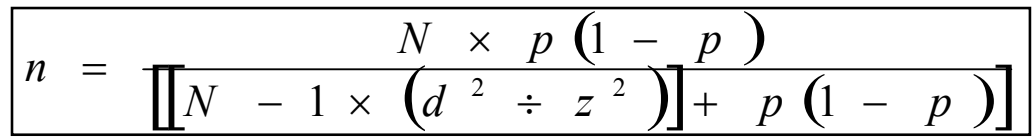

$\mathrm{N}=$ total patient population size

$\mathrm{Z}=$ confidence levels is 0.95 and is equal to 1.96

$\mathrm{D}=$ the error ratio is $=0.05$

$\mathrm{P}=$ the property availability ratio and neutral $=0.50$

\subsection{Tools:}

Three tools were utilized for data collection.

5.4.1. Tool I: Structured Interview Patients' Questionnaire: This tool developed by the researchers and it included two parts:

Part one: Demographic characteristics about the patients: To assess patient data about age, gender, occupation, and level of education, past medical history data include cause of low back pain, duration of pain, and if patient undergo previous radiofrequency session.

Part two: Patients' knowledge assessment: To assess patients' knowledge regarding radiofrequency ablation therapy for chronic low back pain treatment. It comprises three sections;

Section one: used to assess patients level of knowledge as regard to: radiofrequency ablation therapy information such as definition of RFA, types, indications, contraindications, and risks.

Section two: Pre procedural instructions such as pre investigation, stopping medication, eating and drinking restriction, and schedule for a follow-up appointment.

Section three: Post procedural instructions such as length of hospitalization, duration of the procedure, potential post adverse effects, and care at home such as activities, diet, medication, bathing, and follow up

- This part applied pre and after 3 months of the teaching program implementation.

\section{Scoring system:}

Thirteen questions for assessing patients' knowledge regarding radiofrequency ablation therapy for chronic low back pain treatment.

The answer divided into know $=$ one mark and do not know $=$ zero.

Total score was ranged from 0 to 13 and this score classified into three levels: less than $50 \%$ had poor knowledge, $50 \%-70 \%$ had fair knowledge, and more than $70 \%$ had good knowledge.

5.4.2. Tool II: Visual Analogue Pain Scale: It was adopted from (Bain et al., 2005) and used by the researchers to assess the patients' level of pain intensity. The measurement was from zero to ten, in which zero means no pain while ten represents the worst pain. The patient verbally selects a value that is most in line with the intensity of pain that they have experienced in the last 24 hours.

- This tool applied pre and after 3 months of the teaching program implementation.

The scoring system consists of score from 1 to 3 denoted mild pain, a score from 4 to 6 denoted moderate pain and score from 7 to 10 indicated worst pain.

5.4.3. Tool III: "Modified Oswestry Low Back Pain Disability Questionnaire": It was adopted from (Fairbank \& Pynsent, 2000) and modified by the researchers to assess the effect of patient's low back pain on the activities of daily living. It includes 10 sections to describe the pain and its impact on the activities of daily living such as pain intensity, personal care, walking, lifting, sitting, standing, sleeping, social life, travelling and employment), and each containing 6 statements related to limitations in daily activities.

- This tool applied pre and after 3 months of the teaching program implementation.

\section{Scoring system:}

Each section scored from zero to five with higher values indicating severe effect on activities of daily living then all points in all sections were summed up and plug it into the following formula in order to calculate level of disability $=$ Total point $/ 50 \times 100=\%$

Interpretation of scores:

\begin{tabular}{|l|l|}
\hline $\begin{array}{l}\mathbf{0 \%} \text { to 20\%: } \\
\text { Minimal disability. }\end{array}$ & $\begin{array}{l}\text { The patient can cope with most living activities. Usually no treatment is indicated, } \\
\text { apart from advice on lifting, sitting and exercise. }\end{array}$ \\
\hline $\begin{array}{l}\text { 21\%-40\%: Moderate } \\
\text { disability. }\end{array}$ & $\begin{array}{l}\text { The patient experiences more pain and difficulty with sitting, lifting and standing. } \\
\text { Travel and social life are more difficult and they may be disabled from work. Personal } \\
\text { care, and sleeping are not grossly affected and the patient can usually be managed by } \\
\text { conservative means. }\end{array}$ \\
\hline $\begin{array}{l}\mathbf{4 1 \% - 6 0 \% : ~ S e v e r e ~} \\
\text { disability. }\end{array}$ & $\begin{array}{l}\text { Pain remains the main problem in this group but activities of daily living are affected. } \\
\text { These patients require a detailed investigation. }\end{array}$ \\
\hline
\end{tabular}




\begin{tabular}{|l|l|}
\hline 61\%-80\%: Crippled & Back pain impinges on all aspects of the patient's life. Positive intervention is required \\
\hline $\begin{array}{l}\text { 81\%-100\%: } \\
\text { (Bed bounds or } \\
\text { exaggerating). }\end{array}$ & These patients are either bed-bound or exaggerating their symptoms. \\
\hline
\end{tabular}

\subsection{Structured Nursing Teaching Program:}

It was prepared by the researchers based on reviewing recent literature and opinion of the medical and nursing expertise. It was designed in a simplified Arabic language and was supported by photo illustrations and colored pictures. It comprises: knowledge about definition of RFA, types, indications, contraindications, risks, nursing instruction before the procedure such as pre investigation, stopping medication, eating and drinking restriction, and schedule for a follow-up appointment, nursing teaching after the procedure such as length of hospitalization, duration of the procedure, potential post adverse effects, care at home such as activities, diet, medication, bathing, pain site care, follow up. Likewise, it included pictures on helpful hints for a healthy back when standing and walking, driving, coughing / sneezing, sitting, sleeping, lifting, working-standing, and working-stooping.

\subsection{Method:}

\subsubsection{Administrative approval:}

Official approval was obtained from the head of anesthesia and pain management department to collect the data after explaining the aim and nature of the study. Development of tools developed after extensive literature review. 5.6.2. Validity and reliability:

Tool I and III were checked by 5 experts from the medical-surgical nursing field and anesthesia and pain management for content validity. The reliability tested for tools (Patient Interview Questionnaire Sheet) by using Cronbach's alpha coefficient $\alpha 0.85$.

5.6.3. Pilot study:

A pilot study was conducted during June 2018. It included 6 patients (10\% of the total subjects) to test the clarity and applicability of the tools, no modification was done so those patients were included in the main study.

\subsection{Ethical considerations:}

The study followed the common ethical guidelines of clinical research according to the principles of Helsinki Declaration for medical research, (1996). Research proposal becomes accepted by Ethical Committee within the College of Nursing. There is no hazard for study subject during application of the research. The study was complying with ethical principles in clinical research. Oral consent acquired from patients or guidance that are willing to participate in the study, after explaining the aim of the study. Study subject has the right to refuse to participate and or withdraw from the study with no rational any time and privacy have been taken into consideration for the collection of data. The control group received the same structured teaching program booklet at the end of the study.

\subsection{Data collection:}

- Data were collected over a period of 6 months starting from July 2018 till the end of December 2018.

- Data collection was done through the following phases:

\subsubsection{Phase I: Preparatory phase:}

Needed administrative permissions were obtained, assessment of the study setting for possibility of meeting patients for assessment and implementation of the teaching program, development of tool (I) after reviewing the related literature, patients were interviewed individually for assessment using the pre-mentioned study tools (I, II, and III). 5.8.2. Phase II: planning phase: the researchers set the general and specific objectives of the teaching program.

The general objectives of the teaching program:

To acquire patients' knowledge regarding low back pain and radiofrequency ablation and decrease both pain intensity and physical disability after implementation of structured nursing teaching program.

Specific objectives: At the end of the teaching program sessions the patients will be able to:

- Identify RFA, types, indications, contraindications and risks

- Explain nursing instructions before the procedure such as pre investigation, stopping medication, eating and drinking restriction,

- Schedule a follow-up appointment

- Discuss nursing instruction after the procedure such as length of hospitalization, duration of the procedure, potential post adverse effects,

- Apply the activities for a healthy back when standing and walking, driving, coughing / sneezing, sitting, sleeping, lifting, working-standing, and working-stooping. 
- Comply with diet, medication, bathing, pain site care,

- Conduct follows up, it included pictures on helpful hints

\subsubsection{Phase III: Implementation phase:}

Case group patients received structured teaching program which was explained to them by the researchers and they were given a copy of structured teaching program booklet, while those patients in the control group received radiofrequency ablation only. structured nursing teaching program was given to the patients in one session in the pain unite; this session took about 30 minutes with each patient including 15 minutes for discussion and feedback.

\subsubsection{Phase IV: Evaluation phase:}

This phase was conducted after 3 months of structured nursing teaching program implementation for evaluating the effectiveness of it on outcomes of chronic low back pain patients (knowledge, pain intensity, and functional disability (tool I, II, and III) through interviewing the patients in the follow up session of radiofrequency ablation in the pain unite.

\section{Statistical analysis:}

The data were tested for normality using the Anderson-Darling test and for homogeneity variances prior to further statistical analysis. Categorical variables were described by number and percent $(\mathrm{N}$, \%), where continuous variables described by mean and standard deviation (Mean, SD). Chi-square test OR fisher exact test used to compare between categorical variables where compare between continuous variables by Mann-Whitney Test, independent t-test. Two-tailed $\mathrm{p}<0.05$ was considered statistically significant. All analyses were performed with the IBM SPSS 20.0 software and excel sheet data base version 2016.

\section{Results:}

Table (1) presents demographic characteristics of the studied sample. As regard sex the highest percentages in both groups were females. Regarding residence; the table found that the highest percentages in both groups (case and control) were living in rural areas. Regarding age; it was found that more than half of both case and control groups $(53.3 \%)$ and $(56.6 \%)$ respectively their age was from 18 to $<55$ years and the rest of them were older adults. Regarding education, it was found that (66.7\%) of the case group had secondary education, while (50\%) of the control group was able to read and write. The highest percentages in both groups were married, not working; duration of their pain from 1-5 years and do not had radiofrequency sessions before that. Regarding low back pain causes, it were found that the most cause was discogenic low back pain in case group while in the control group; lumber facet joint was the main cause $(66.7 \%$ and $50 \%$ respectively).

Fig (1) describes that $(80 \%)$ of the case group had good knowledge post implementation of structured teaching program, while $(16.7 \%)$ of the control group had fair level of knowledge. There was a significant difference between case and control groups post implementation of structured teaching program with P. value $<0.001$.

Fig (2) displays that all patients (100\%) of the case group had worst pain intensity level which decreased to $(46.7 \%)$ after implementation of structured nursing teaching program, while (28\%) of the control group had worst pain intensity level which increased to $(73.3 \%)$ after three months. There was a significant difference between case and control group post implementation of structured nursing teaching program with $\mathrm{p}$ value 0.032 .

Fig (3) illustrates that (40\%) of case group had sever disability, which decreased to (30\%) post implementation of structured nursing teaching program, while $(36.7 \%)$ of control group had moderate disability which increased to $(63.3 \%)$ after three months. There was a significant difference in case and control groups in pre and post implementation of structured nursing teaching program with $\mathrm{p}$ value $<0.001$.

Table (2) reflects that; there were significant relation between pain analogue scale and Oswestry low back pain disability scale in pre and post structured nursing teaching program regarding to occupation. 
Table (1) Distribution of the studied sample (case and control groups) as regards demographic characteristics $(\mathbf{N o}=60)$

\begin{tabular}{|c|c|c|c|c|c|}
\hline \multirow{2}{*}{ Demographic characteristics } & \multicolumn{2}{|c|}{ Case $(n o=30)$} & \multicolumn{2}{|c|}{ Control $(n o=30)$} & \multirow{2}{*}{ P. value } \\
\hline & No & $\%$ & No & $\%$ & \\
\hline \multicolumn{6}{|l|}{ Gender: } \\
\hline Male & 12 & 40.0 & 6 & 20.0 & \multirow{2}{*}{$0.159^{\mathrm{ns}}$} \\
\hline Female & 18 & 60.0 & 24 & 80.0 & \\
\hline \multicolumn{6}{|l|}{ Residence: } \\
\hline Urban & 6 & 20.0 & 9 & 30.0 & \multirow{2}{*}{$0.371^{\mathrm{ns}}$} \\
\hline Rural & 24 & 80.0 & 21 & 70.0 & \\
\hline \multicolumn{6}{|l|}{ Age: } \\
\hline $18<55$ years & 16 & 53.3 & 17 & 56.6 & \multirow{2}{*}{$0.473^{\mathrm{ns}}$} \\
\hline$\geq 55$ years & 14 & 46.7 & 13 & 43.3 & \\
\hline Mean \pm SD & \multicolumn{2}{|c|}{$47.13 \pm 13.34$} & \multicolumn{2}{|c|}{$46.90 \pm 11.63$} & $0.942^{\mathrm{ns}}$ \\
\hline \multicolumn{6}{|l|}{ Educational Level: } \\
\hline Read and write & 6 & 20.0 & 15 & 50.0 & \multirow{3}{*}{$0.050^{\mathrm{ns}}$} \\
\hline Secondary education & 20 & 66.7 & 13 & 43.3 & \\
\hline University & 4 & 13.3 & 2 & 6.7 & \\
\hline \multicolumn{6}{|l|}{ Marital Status: } \\
\hline Single & 2 & 6.7 & 4 & 13.3 & \multirow{2}{*}{$0.667^{\mathrm{ns}}$} \\
\hline Married & 28 & 93.3 & 26 & 86.7 & \\
\hline \multicolumn{6}{|l|}{ Occupation: } \\
\hline Working & 8 & 26.7 & 4 & 13.3 & \multirow{2}{*}{$0.197^{\mathrm{ns}}$} \\
\hline Not working & 22 & 73.3 & 26 & 86.7 & \\
\hline \multicolumn{6}{|l|}{ Cause of low back pain: } \\
\hline Lumbar facet joints & 6 & 20.0 & 15 & 50.0 & \multirow{3}{*}{$0.060^{\mathrm{ns}}$} \\
\hline Discogenic low back pain & 20 & 66.7 & 13 & 43.3 & \\
\hline Sacroiliac joints & 4 & 13.3 & 2 & 6.7 & \\
\hline \multicolumn{6}{|l|}{ Duration of pain: } \\
\hline Less than 1 year & 12 & 40.0 & 13 & 43.3 & \multirow{3}{*}{$0.829^{\mathrm{ns}}$} \\
\hline from $1-5$ year & 16 & 53.3 & 14 & 46.7 & \\
\hline more than 5 year & 2 & 6.7 & 3 & 10.0 & \\
\hline \multicolumn{6}{|c|}{ Obtaining sessions of radio-frequency ablation before that: } \\
\hline No & 28 & 93.3 & 24 & 80.0 & \multirow{2}{*}{$0.129^{\mathrm{ns}}$} \\
\hline Yes & 2 & 6.7 & 6 & 20.0 & \\
\hline
\end{tabular}

- Chi-square test.
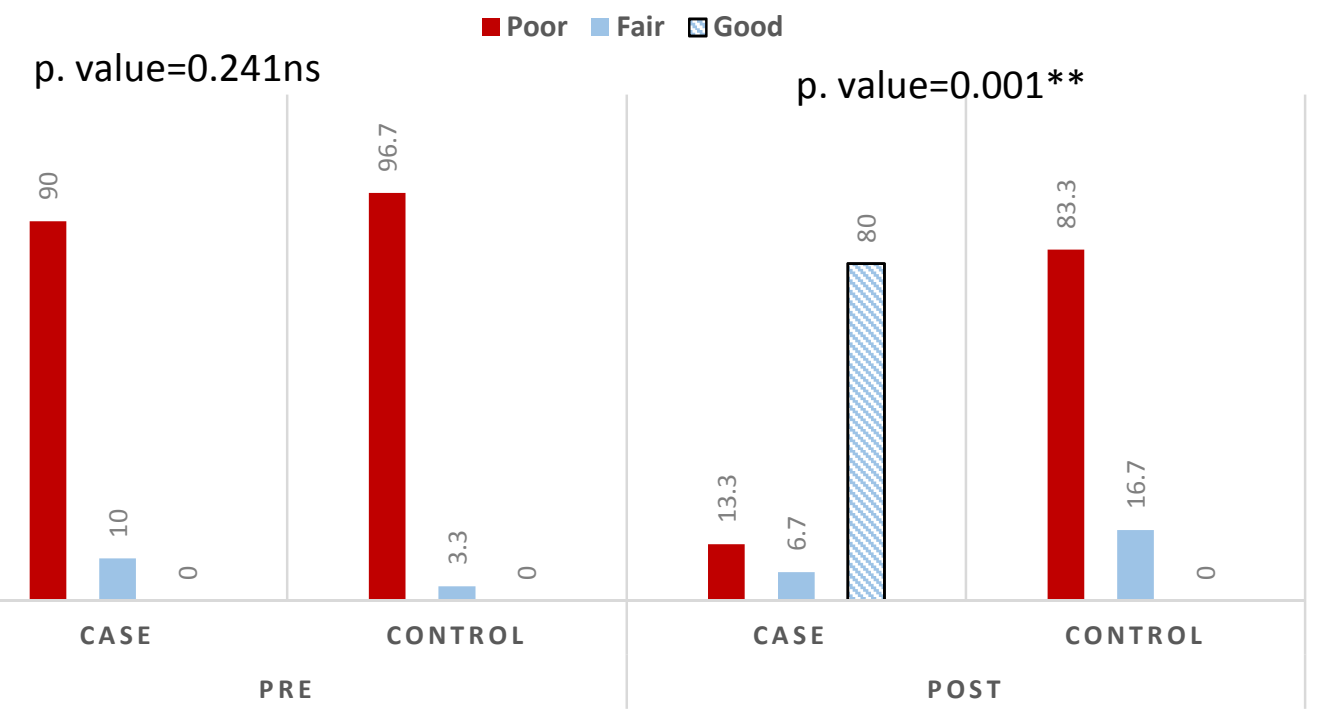

Fig (1); The total patients' knowledge scores level of the case and control groups in pre and post implementation of structured nursing teaching program $(\mathrm{No}=60)$ 


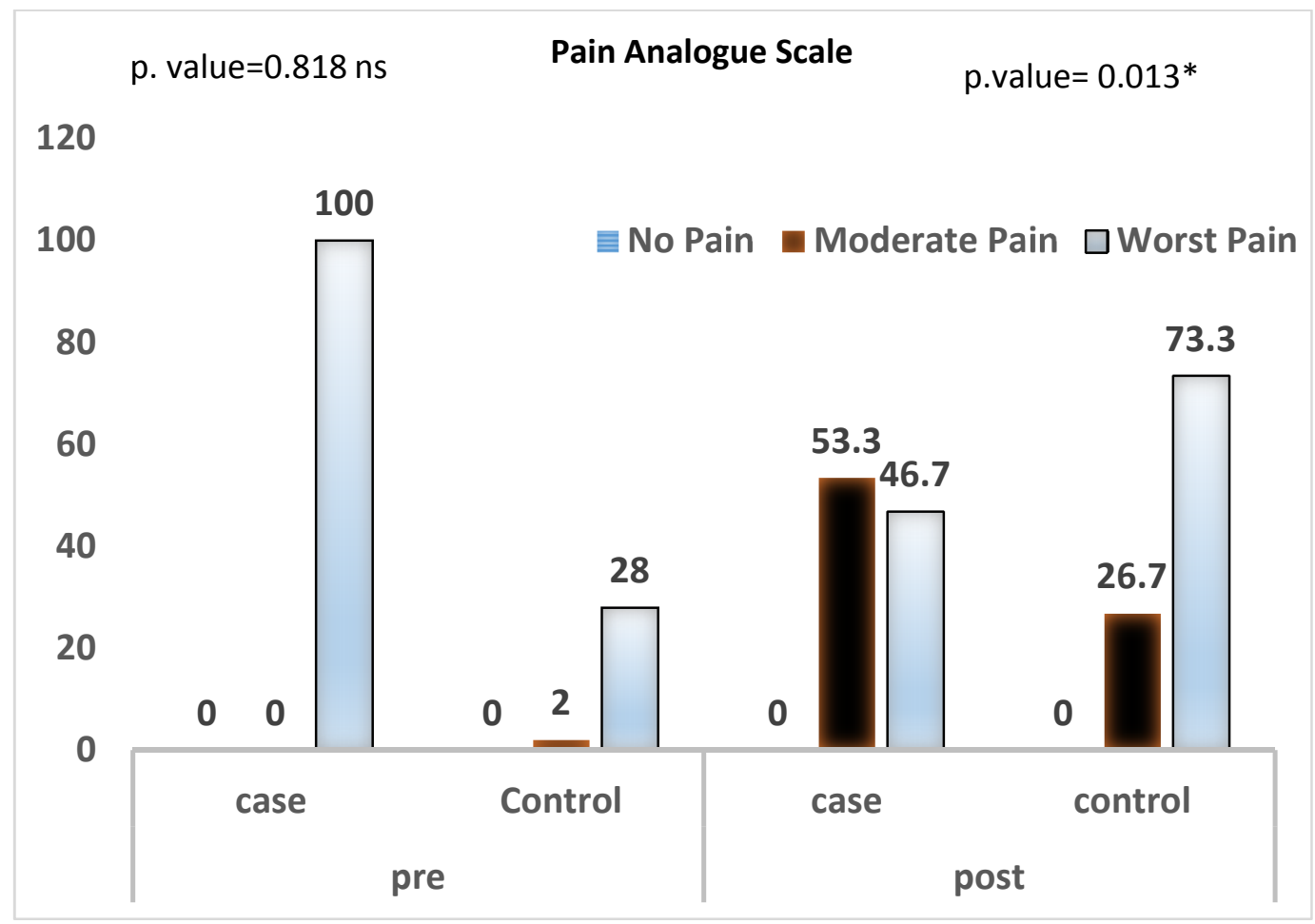

Fig (2): pain intensity levels of the studied two groups pre and post implementation of structured nursing teaching program $(\mathrm{No}=60)$

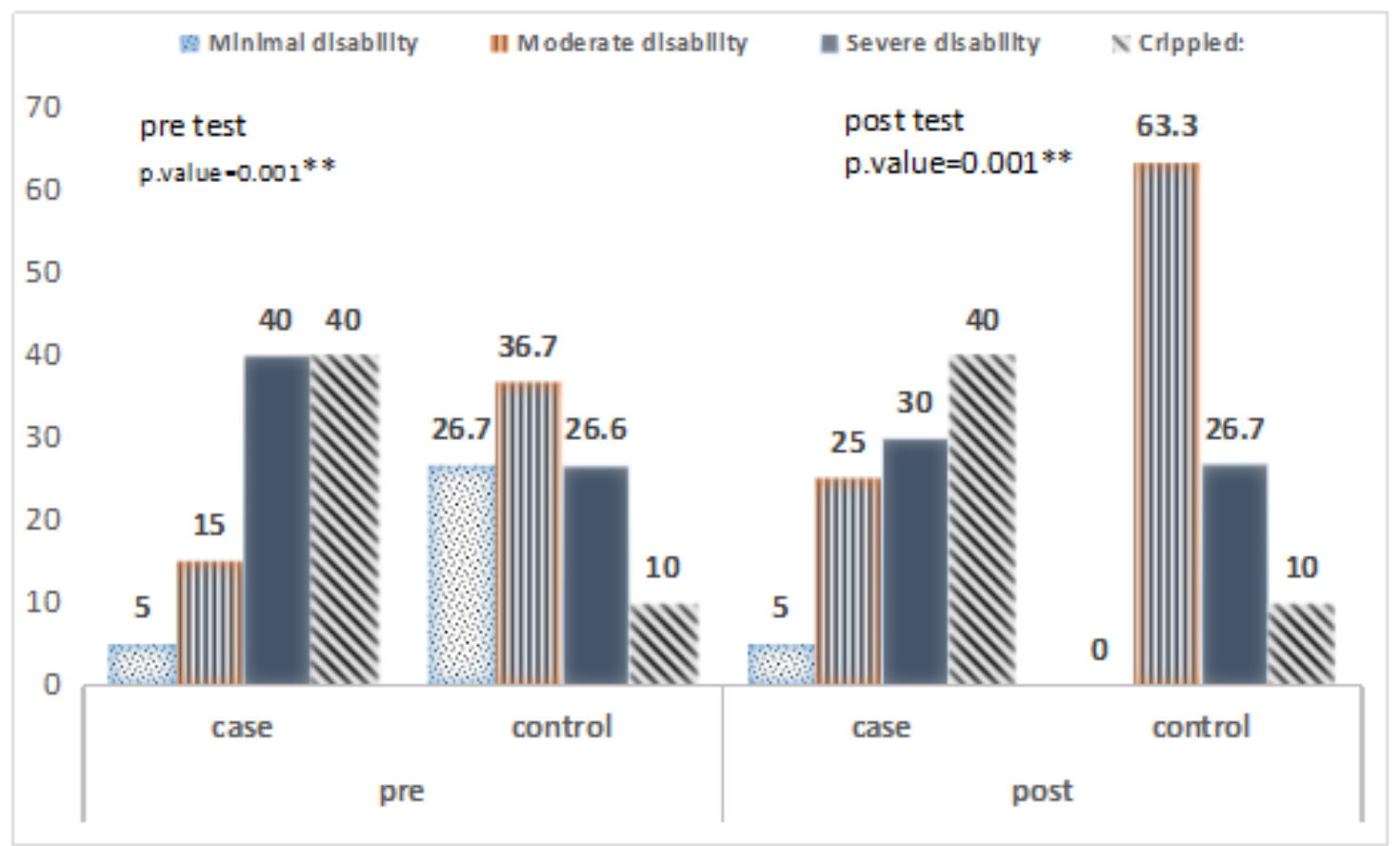

Fig (3) Oswestry low back pain disability scale level in case and control groups pre and post implementation of structured nursing teaching program $\left(\mathrm{No}^{\circ}=\mathbf{6 0}\right)$ 
Table (2) Relation between case group's pain analogue scale, Oswestry low back pain disability scale and knowledge scores with their demographic data pre and post implementation of structured nursing teaching $\operatorname{program}(\mathbf{N} .=60)$

\begin{tabular}{|c|c|c|c|c|c|c|}
\hline \multirow{3}{*}{$\begin{array}{l}\text { Demographic } \\
\text { characteristics }\end{array}$} & \multicolumn{2}{|c|}{ Pain Analogue Scale } & \multicolumn{2}{|c|}{$\begin{array}{c}\text { Oswestry Low Back Pain } \\
\text { Disability Scale }\end{array}$} & \multicolumn{2}{|c|}{ Knowledge scores } \\
\hline & Pre test & post test & Pre test & post test & Pre test & post test \\
\hline & Mean \pm SD & Mean \pm SD & Mean \pm SD & Mean \pm SD & Mean \pm SD & Mean \pm SD \\
\hline \multicolumn{7}{|l|}{ Age: } \\
\hline $18<55$ years & $8.75 \pm 0.45$ & $3.83 \pm 2.05$ & $35.19 \pm 4.04$ & $15.5 \pm 6.36$ & $5.62 \pm 1.41$ & $11.5 \pm 1.22$ \\
\hline$\geq 55$ years & $9.2 \pm 0.42$ & $5.8 \pm 2.12$ & $35 \pm 8.22$ & $21.3 \pm 9.96$ & $6 \pm 1.7$ & $8.5 \pm 1.87$ \\
\hline P. value & 0.113 & $0.042 *$ & 0.290 & 0.121 & 0.515 & $0.001 * *$ \\
\hline \multicolumn{7}{|l|}{ Gender: } \\
\hline Male & $8.67 \pm 0.69$ & $5.44 \pm 2.12$ & $33.78 \pm 8.24$ & $21.94 \pm 10.62$ & $6 \pm 2.25$ & $11.28 \pm 1.32$ \\
\hline Female & $9 \pm 0.6$ & $3.67 \pm 2.57$ & $36.33 \pm 5.03$ & $14.83 \pm 9.41$ & $5.25 \pm 0.62$ & $10 \pm 2.09$ \\
\hline P. value & 0.183 & $0.048 *$ & 0.346 & 0.071 & 0.272 & 0.049* \\
\hline \multicolumn{7}{|l|}{ Residence: } \\
\hline Urban & $9 \pm 0$ & $5.33 \pm 2.58$ & $31.67 \pm 7.23$ & $14 \pm 8.81$ & $5.67 \pm 0.52$ & $11.17 \pm 1.17$ \\
\hline Rural & $8.75 \pm 0.74$ & $4.58 \pm 2.43$ & $35.58 \pm 7.06$ & $20.38 \pm 10.78$ & $5.71 \pm 2.01$ & $10.67 \pm 1.88$ \\
\hline P. value & 0.419 & 0.509 & 0.236 & 0.192 & 0.961 & 0.542 \\
\hline \multicolumn{7}{|l|}{ Marital Status: } \\
\hline Single & $9 \pm 0$ & $2 \pm 0$ & $39 \pm 0$ & $3 \pm 0$ & $6 \pm 0$ & $12 \pm 0$ \\
\hline Married & $8.79 \pm 0.69$ & $4.93 \pm 2.4$ & $34.5 \pm 7.31$ & $20.25 \pm 10$ & $5.68 \pm 1.87$ & $10.68 \pm 1.79$ \\
\hline P. value & 0.667 & 0.101 & 0.399 & $0.023 *$ & 0.812 & 0.312 \\
\hline \multicolumn{7}{|l|}{$\begin{array}{l}\text { Educational } \\
\text { Level: }\end{array}$} \\
\hline Read and write & $9.33 \pm 0.52$ & $5.67 \pm 2.16$ & $41.67 \pm 3.72$ & $22 \pm 11.63$ & $5.33 \pm 0.52$ & $8.5 \pm 1.87$ \\
\hline $\begin{array}{l}\text { Secondary } \\
\text { education }\end{array}$ & $8.6 \pm 0.68$ & $4.2 \pm 2.59$ & $32 \pm 6.85$ & $16.6 \pm 10.33$ & $5 \pm 0.79$ & $11.15 \pm 1.23$ \\
\hline University & $9 \pm 0$ & $6 \pm 1.15$ & $38.5 \pm 2.89$ & $27.25 \pm 6.08$ & $9.75 \pm 1.26$ & $12.25 \pm 0.5$ \\
\hline P. value & 0.043* & 0.238 & $0.004 * *$ & 0.140 & $<0.001 * *$ & $<0.001 * *$ \\
\hline \multicolumn{7}{|l|}{ Occupation: } \\
\hline Working & $8.25 \pm 0.89$ & $3 \pm 2.14$ & $28.75 \pm 5.73$ & $11.75 \pm 8.56$ & $6 \pm 2.83$ & $11.63 \pm 0.92$ \\
\hline Not working & $9 \pm 0.44$ & $5.36 \pm 2.26$ & $37 \pm 6.37$ & $21.77 \pm 10.13$ & $5.59 \pm 1.33$ & $10.45 \pm 1.9$ \\
\hline P. value & $0.004 * *$ & $0.016 *$ & $0.003 * *$ & 0.019* & 0.592 & 0.107 \\
\hline \multicolumn{7}{|l|}{$\begin{array}{l}\text { Duration of } \\
\text { pain: }\end{array}$} \\
\hline Less than 1 year & $9 \pm 0.6$ & $4.5 \pm 2.11$ & $33.83 \pm 7.09$ & $19.67 \pm 8.81$ & $5.25 \pm 0.62$ & $10.33 \pm 2.15$ \\
\hline from 1-5 year & $8.63 \pm 0.72$ & $4.63 \pm 2.73$ & $34.75 \pm 7.48$ & $17 \pm 11.45$ & $5.63 \pm 2.06$ & $10.94 \pm 1.48$ \\
\hline more than 5 year & $9 \pm 0$ & $7 \pm 0$ & $41 \pm 0$ & $32.5 \pm 0.71$ & $9 \pm 1.41$ & $12 \pm 0$ \\
\hline P. value & 0.315 & 0.405 & 0.437 & 0.145 & 0.018* & 0.407 \\
\hline
\end{tabular}

- Independent t-test *Significant difference at p. value $<0.05$

- ANOVA test $*$ Significant difference at $\mathrm{p}$. value $<0.05,{ }^{*}$ Significant difference at $\mathrm{p}$. value $<0.01$

\section{Discussion:}

Low back pain (LBP) is one of the most common etiologies of disability. The main aim of this study was to evaluate the effectiveness of structured nursing teaching program on outcomes of chronic low back pain patients undergoing radiofrequency ablation.

Regarding the demographic characteristics of the studied groups, the present study findings represented that the highest percent of case and control group were females. This can be attributed to the accumulation of household chores and outside work, in addition to women's anatomical and functional characteristics. These study findings are in the line with Abreu and Ribeiro, (2010) who instituted that although many studies not described significant differences in chronic low back pain between genders, the prevalence was higher in women. Moreover, this was on the contrary with Weheida et al., (2016) who pointed that the prevalence of low back pain affects a large proportion of the male population.

The existing study also, showed that more than half of studied patients have an age ranged from (18 to less than 55 years old and less than half of studied patients were older adults that their age from 55 and more. This finding was supported by McGregor et al., (2010) who explained that after the age of thirty the intervertebral 
disks tend to lose their moisture content and become thinner as people get older and become prone to injury. On the other hand, Hartvigsen et al., (2018) reported that low back pain affects all age groups from children to the elderly population.

Concerning educational level, the current study denoted that about two thirds of the case groups have secondary level of education. According to Barbosal et al., (2018) revealed the results, where that more than half of the patients had 6 to 11 years of formal schooling. Mbizo et al., (2019) pointed that; a low level of education is associated with various diseases and condition, including musculoskeletal disorders and more specifically low back pain. Moreover, in a study of Smart, (2018) which found that; low back pain was strongly associated with level of education, this finding consistent with the result of this article which revealed that; there is a significant relation between educational level and low back pain. In the other hand Hartvigsen et al., (2018) found there is no relation between education and low back pain.

In relation to residence, the majority of the case groups were from rural area, this finding is consistent with Lahelma et al., (2012) \& Abd Elwahhab, (2015) who observed that low back pain is most common in patients from rural area that can be due to a number of factors including working conditions such as heavy physical work and dynamic working postures, as well as manual handling and lifting. The study finding denoted also that the majority of the studied groups were married. This finding was supported with prior study by Weheida et al., (2016) which has shown that the risk of low back pain was higher in married patients.

Regarding low back pain cause, it was found that the most cause was discogenic low back pain in case group. This finding was in agreement with Jose et al., (2018) who found that chronic discogenic low back pain (CDP) is frequently diagnosed in patients referred to specialized pain clinics for their back pain. This is attributed to degenerative changes in the intervertebral disc due to aging or to traumatic events. This finding not in the same line with Krappel et al., (2017) who found that the most cause of low back pain was herniectomy with or without diam spinal stabilizing device. As for the duration of pain, it was observed that more than half of the sample had been having chronic back pain from 1-5years. Similar length of time was found in a study about low back pain Pedro \&Suely,(2015), in which was observed that most of subjects had been having low back pain for more than 24 months. In accordance with Beresford et al., (2010) reported that persistent low back pain for more than six weeks can disables more than two fifth of the subjects with such clinical conditions. This warns the chronicity of the disease, also reflecting the failures in the therapeutic method.

Regarding patient's knowledge pre and post implementation of structured nursing teaching program, it was found that there was a significant difference between case and control group after implementation of structured teaching program with $\mathrm{p}$ value $<0.001$. This result of study coincided with the study of Ibrahim and Elsaay, (2015) who reported that the mean knowledge scores of the patients immediately and after 3 months of the intervention were higher than their pre training scores, and this difference was statistically significant.

In this regard, Piper et al., (2016) concluded that several studies have investigated the effectiveness of different treatment protocols to decrease musculoskeletal disorders. These include introducing education programs, ergonomic changes in work settings, relaxation programs, exercise programs, and multidisciplinary team approaches. In addition, these findings were in agreement with Zhang et al., (2014). They reported that the health education intervention is effective for improving pain and disability in patients with chronic low back pain. Conversely with the current study Demoulin et al., (2012) stated that a critical review of nine randomized controlled clinical trials found no effect of education on preventing low back pain.

In the present study, the pain intensity scores and Oswestry low back pain disability scores showed significant $(\mathrm{P}<0.032<0.001$ respectively) improvement after 3 months post implementation of structured teaching program. These findings congruent with Prasad (2010) who pointed that education program consisting of information about radiofrequency ablation procedures, and some helpful hints for a healthy back when standing and walking, driving, coughing / sneezing, sitting, sleeping, lifting, working-standing, and working-stooping will help the patients adopt correct body alignment in working place and at home and reduce the functional disability. Moreover, this study finding was in line with Lewis and Flynn, (2001) and Dhaliwal et al., (2014). They detected that improvement in the outcomes measures for disability levels (Oswestry Low Back Pain Disability Questionnaire) and pain (Mc Gill Pain Questionnaire) in all cases after teaching program application.

The current study findings revealed that there were significant relation between pain analogue scale, Oswestry low back pain disability scale, and knowledge scores pre and posttest with regard to age, gender, educational level, occupation and marital status.

This result was incompatible with Nicholl et al., (2017) who reported that patients' age affect on pain and knowledge level, but Teut et al., (2018) results showed that gender and their age significantly affect on level of patients' pain, and Oswestry low back pain disability scale, adding natural biochemical changes that can occur with age because disc gradually dries out that which may affect disc strength and reduction of low back pain among post-menopausal women. It proved that, age and accompanying degeneration results in loss of elasticity of the discs.

The significant relation between aging, pain intensity and higher frequency of disability, which related to 
physiological changes; aging may result in progressive degenerative changes of the spinal column. It may result in to wear of the musculoskeletal system causing painful episodes which suggested that older individuals have greater risks to problems in the lumber spine.

The significant relation between the patients' age groups and their knowledge level post application of structured nursing teaching program may be related to cognitive changes among patients aged fifty-five and more which affected by their diminished learning abilities.

Finally, these finding has been confirmed that; structured nursing teaching program implementation significantly improved the patients' outcomes through increasing patients' knowledge, and decreasing both pain intensity and physical disability in the case group versus the control group that achieved its hypotheses.

\section{Limitations of the study:}

Our study has two main limitations. First, the sample size was small, limiting the value of the findings. Second, there was no long-term follow-up in our study.

\section{Conclusion:}

These finding has been confirmed that; the structured nursing teaching program had an effective strategy to improve the patients' outcomes through increasing patients' knowledge, and decreasing both pain intensity and physical disability in the case group versus the control group

\section{Recommendations:}

1. Supervised structured nursing teaching program should be carried out in anesthesia and pain management department at Assiut University Hospital about pre-procedure instructions, Post procedure instructions and helpful hints for a healthy back when standing and walking, driving, coughing / sneezing, sitting, sleeping, lifting, working standing, and working-stooping.

2. Further research is necessary, as well as, larger sample size.

Declaration of interest:

The authors do not mention any conflict of interest. Only the authors are responsible for the content of the paper.

\section{References:}

1. Abd Elwahhab A. (2015): Effect of superficial hot versus cold application on low back pain among patients with disk prolapse. Unpublished Master Thesis, Faculty of Nursing, Menoufia University, P. 34

2. Abreu A.T., \&Ribeiro, C.A. (2010): Prevalência de lombalgia em trabalhadores submetidos ao programa de reabilitação profissional do Instituto Nacional do Seguro Social (INSS), São Luís, MA. Acta Fisiatr.;17(4), p.p. 148-52.

3. Bain G., Kuwahata T., Raymod B., \& Foster, R. (2005):Tea Tree hydrogel dressing used in wound care, available at:// www.ridc.gov.aul reports/ tt , p.p. 105-114

4. Barbosal F. M., Érica Brandão de Moraes Vieira, \&João Batista Santos Garcia Br J Pain.(2018): Beliefs and attitudes in patients with chronic low back pain, apr-jun;1(2), p.p. 116-21.

5. Beresford Z.M., Kendall R.W., Willick S.E. (2010): Lumbar facet syndromes. Curr Sports Med Rep.;9: p.p. 50-56.

6. Crystian B., Oliveira Chris G., Maher, Rafael Z., Pinto, Adrian C. Traeger, Chung-Wei Christine Lin ·Jean-Francois Chenot · Maurits van Tulder · \&Bart W. Koes. (2018): Clinical practice gudelines for the management of non-specific low back pain in primary care: an updated overview. European Spine Journal 27, P.P. 2791-2803. https://doi.org/10.1007/s00586-018-5673-2

7. Demoulin C., Marty M., \&Genevay S. (2012): Effectiveness of preventive back educational interventions for low back pain: a critical review of randomized controlled clinical trials. Eur Spine J; 21, P.P. 2520-2530.

8. Dhaliwal M.K., Amandeep, Jagmohan, \&Manjeet. (2014): To compare the effects of proprioceptive neuromuscular facilitation program versus core statbilization exercises for decreasing pain and improving functions in patients with low back pain. IOSR J Sports Physical Education.;1(5)p.p:29-35.

9. Fairbank, J. and Pynsent, P., (2000): The Oswestry Disability Index. Spine, 25 (22), P.P.400- 520.

10. Gomes G.C., Salmela L.F.T, Fonseca B.E, Freitas F.A.Z, Fonseca, M.L.M, \&Pacheco B.D.( 2015): Age and education influence the performance of elderly women on the dual-task Timed Up and Go test. Arq Neuropsiquiatr.;73(3)p.p.187-93

11. Hartvigsen, J., Hancock, M. J., Kongsted, A., Louw, Q., Ferreira, M. L., Genevay, S., ... \& Smeets, R. J. (2018): What low back pain is and why we need to pay attention. The ancet, 391(10137), 2356-2367.

12. Helsinki F., (1996): World medical association declaration of Helsinki , Recommendations guiding physicians in biomedical research involving human subjects, Adopted by the $18^{\text {th }}$ World Medical Assembly, P.P. 17c.

13. Hofmann U.K., Keller R.L., Walter C., \&Mittag F. (2017): Predictability of the effects of facet joint infiltration in the degenerate lumbar spine when assessing MRI scans. J Orthop Surg Res, p.p. 12. 
14. Ibrahim E., \& Elsaay, O. (2015): The Effect of Body Mechanics Training Program for Intensive Care Nurses in Reducing Low Back Pain. IOSR Journal of Nursing and Health Science, 4 (5), p.p. 81-96.

15. Imani F., \&Safari S.(2011): "Pain Relief is an Essential Human Right", We Should be Concerned about It. Anesth Pain Med.1(2):p.p55-7. doi: 10.5812/kowsar.22287523.2306. [PubMed: 25729655].

16. Jose W. Geurts, Paul C. Willems, Jan-Willem Kallewaard, Maarten van Kleef, \& Carmen Dirksen.(2018): The Impact of Chronic Discogenic Low Back Pain: Costs and Patients' Burden. Hindawi ,Pain Research and Management, Volume 2018, Article ID 4696180, P. 8 https://doi.org/10.1155/2018/4696180.

17. Kapural L, Vrooman B, Sarwar S, Krizanac-Bengez L, Rauck R,\& Gilmore C.(2017): A randomized, placebo-controlled trial of transdiscal radiofrequency, iacuplasty for treatment of discogenic lower back pain. Pain Med. 14:p.p362-73. [PubMed]

18. Kapural L., Vrooman B., \&Sarwar S. (2013): A randomized, placebo-controlled trial of transdiscal radiofrequency, biacuplasty for treatment of discogenic lower back pain. Pain Med.;14, p.p. 362-73.

19. Kennedy J. M., Roll T., Schraudner S., Murphy S., \&McPherson. (2014): "Prevalence of persistent pain in the U.S. adult population: new data from the 2010 national health interview survey," Journal of Pain, vol. 15, no. 10, p.p. 979-984

20. Koes B.W., Van Tulder M., Lin C-W.C., Macedo L.G., McAuley J.,\& Maher C.(2010): An updated overview of clinical guidelines for the management of non-specific low back pain in primary care. Eur Spine J. 19(12):p.p2075-2094

21. Krappel F., Brayda-Bruno, M., Alessi, G., Remacle, J. M., Lopez, L. A., Fernández, J. J., ... \& Pfirrmann, C. W. (2017): Herniectomy versus herniectomy with the DIAM spinal stabilization system in patients with sciatica and concomitant low back pain: results of a prospective randomized controlled multicenter trial. European Spine Journal, 26(3), 865-876

22. Lahelma E., Laaksonen M., Lallukka T., \& Martikainen P. (2012): Environmental conditions as risk factors for disability retirement: a longitudinal register linkage study. BMCpublic health; 12, p.p. $309-318$.

23. Lewis C., \&Flynn T. (2001): The use of strain-counterstrain in the treatment of patients with low back pain. J Man Manipulative There; 9(2), p.p. 92-98.

24. Malekian M, Ghiyasvandian ,S.h, Cheragh, M, Hassanzadeh, A. (2016): Iranian clinical nurses' readiness for self-directed learning Global journal of health science. Global journal of health science.;8(1):P.P.157-64.

25. Mbizo J., Okafor A., Sutton M. A., \& Stone L. M. (2019) Integrative and Complementary Medicine Use in Adults With Chronic Lower Back Pain, Neck Pain, and Arthritis/Musculoskeletal Diseases. In Bioactive Food as Dietary Interventions for Arthritis and Related Inflammatory Diseases(p.p. 37-49). Academic Press.

26. McGregor A.H. Doré C.J. Morris T.P. Morris S., \& Jamrozik K.(2010): Function after Spinal Treatment, Exercise and Rehabilitation (faster): Improving the Functional Outcome of Spinal Surgery, Musculoskeletal Disorders., p.p. 11:17

27. Nicholl B. I., Sandal L. F., Stochkendahl M. J., McCallum M., Suresh N., Vasseljen O.,\& Mair F. S. (2017): Digital support interventions for the self-management of low back pain: a systematic review. Journal of medical Internet research, 19(5), e179.

28. Pedro Henrique Brito da Silva\& Suely Maria Satoko Moriya Inumaru(2015): Assessment of pain in patients with chronic low back pain before and after application of the isostretching method.Fisioter.mov.vol.28no4.print versionIssn0103-15150on-line versionIssn1980-5918.http//dx.doi-org/10-1590/0103-5150.028-004-A014.

29. Piper S., Shearer, H. M., Côté, P., Wong, J. J., Yu, H., Varatharajan, S., \& Nordin, M. C. (2016): The effectiveness of soft-tissue therapy for the management of musculoskeletal disorders and injuries of the upper and lower extremities: A systematic review by the Ontario Protocol for Traffic Injury management (OPTIMa) collaboration. Manual therapy, 21, P.P.18-34.

30. Prasad V. (2010): The effectiveness of structured teaching programme on knowledge regarding intervertebral disc prolapse among loading and unloading workers,Bangalore.:http://www.rguhs.ac.in/cdc/onlinecdc/uploads/05_N007_21410.doc.

31. Smart K. J. (2018): Prevalence, Severity and Career Specific Characteristics Associated with Low Back Pain in Rehabilitation Staff (Doctoral dissertation, Florida Gulf Coast University).Unpublished.

32. Steven K. Thompson ( 2012): Sampling, sample size ,p.p :59-60

33. Teut M., Ullmann A., Ortiz M., Rotter G., Binting S., Cree M., \& Brinkhaus B. (2018): Pulsatile dry cupping in chronic low back pain-a randomized three-armed controlled clinical trial. BMC complementary and alternative medicine, $18(1)$, p.115.

34. Weheida S. M., Abd Elgaphar, S.M., Abd Elalem ,S M.(2016): The Effect of -Implementing an Educational Program about Proper Body Mechanics on Low Back Pain and Activities of Daily Living among Patients with Disc Prolapse. IOSR Journal of Nursing and Health Science (IOSR-JNHS) e-ISSN: 2320-1959.p- ISSN: 23201940 Volume 5, Issue 6 Ver. (II), P.P 59-67 www.iosrjournals.org

35. ZhangY., Wan L., \& Wang, X.(2014): The effect of health education in patients with chronic low back pain, Journal of International Medical Research , Vol. 42(3), P.P. 815-820 